Cite this article as : Willems, J., Khamis, M.M., Saeid, W.M., et al. Anal Chim Acta. 2016 Aug 24; 933:16474. Final publication is available at: http://dx.doi.org/10.1016/j.aca.2016.05.041.

\title{
Analysis of a Series of Chlorogenic Acid Isomers using Differential Ion Mobility and Tandem Mass Spectrometry
}

\author{
Jamie Willems, ${ }^{1}$ Mona M. Khamis, ${ }^{2}$ Waleed Mohammed Saeid, ${ }^{2}$ Randy W. Purves, ${ }^{3}$ George \\ Katselis, ${ }^{4}$ Nicholas Low, ${ }^{1}$ Anas El-Aneed ${ }^{2 *}$ \\ 1. Department of Food and Bioproduct Sciences, College of Agriculture and Bioresources, University of Saskatchewan, 51 Campus Drive, \\ Saskatoon, SK, S7N 1A8, Canada \\ 2. Drug Design \& Discovery Group, College of Pharmacy and Nutrition, University of Saskatchewan, 107 Wiggins Road, Saskatoon, SK S7N \\ $5 E 5$, Canada \\ ${ }^{3 .}$ Crop Development Centre, College of Agriculture and Bioresources, 51 Campus Drive, Saskatoon, S7N 5A8, Canada \\ 4. Canadian Centre for Health and Safety in Agriculture (CCHSA), and Department of Medicine, University of Saskatchewan, 104 Clinic Place, \\ Saskatoon, SK S7N 2Z4, Canada \\ * Please address any correspondence to: \\ Dr. Anas El-Aneed, College of Pharmacy and Nutrition, University of Saskatchewan, 107 Wiggins Road, Saskatoon, SK S7N 5E5, Canada, \\ Phone 1-306-966-2013, email: anas.el-aneed@usask.ca
}

\begin{abstract}
Chlorogenic acids are among the most abundant phenolics found in the human diet. Of these, the mono-caffeoylquinic acids are the predominant phenolics found in fruits, such as apples and pears, and products derived from them. In this research, a comprehensive study of the electrospray ionization (ESI) tandem mass spectrometric (MS/MS) dissociation behavior of the three most common mono-caffeoylquinic acids, namely 5-O-caffeoylquinic acid (5-CQA), 3-Ocaffeoylquinic acid (3-CQA) and 4-O-caffeoylquinic acid (4-CQA), were determined using both positive and negative ionization. All proposed structures of the observed product ions were confirmed with second-generation $\mathrm{MS}^{3}$ experiments. Similarities and differences between the dissociation pathways in the positive and negative ion modes are discussed, confirming the proposed structures and the established MS/MS fingerprints. MS/MS dissociation was primarily driven via the cleavage of the ester bond linking the quinic acid moiety to the caffeic acid moiety within tested molecules. Despite being structural isomers with the same $m / z$ values and dissociation behaviors, the MS/MS data in the negative ion mode was able to differentiate the three isomers based on ion intensity for the major product ions, observed at $\mathrm{m} / \mathrm{z} 191,178$ and 171. This differentiation was consistent among various MS instruments. In addition, ESI coupled with high-field asymmetric waveform ion mobility spectrometry-mass spectrometry (ESI-FAIMS-MS) was employed for the separation of these compounds for the first time. By combining MS/MS data and differential ion mobility, a method for the separation and identification of mono-caffeoylquinic in apple/pear juice samples was developed with a run time of less than one minute. It is envisaged that this methodology could be used to identify pure juices based on their chlorogenic acid profile (i.e., metabolomics), and could also be used to detect juice-to-juice adulteration (e.g., apple juice addition to pear juice).
\end{abstract}


Cite this article as : Willems, J., Khamis, M.M., Saeid, W.M., et al. Anal Chim Acta. 2016 Aug 24; 933:16474. Final publication is available at: http://dx.doi.org/10.1016/j.aca.2016.05.041.

\section{INTRODUCTION}

The term phenolics refers to a class of plant metabolites, which are defined by the presence of at least one phenol functional group.[1-3] Phenolics are ubiquitous in nature and have been reported to have a number of positive functions in plants that include, but are not limited to: protection against pathogens, parasites, predators, ultraviolet radiation and oxidants; cell signalling; attraction of pollinators and seed dispersing animals; and cell wall strengthening.[1, 4-6] In addition, phenolics contribute to the sensory properties of food; for example, phenolics affect the bitterness, astringency and colour of fruit juices.[2, 4, 7]

Due to their structural diversity, phenolics are typically subdivided into a number of structurally related classes. One class is the chlorogenic acids, which are composed of quinic acid linked to trans-cinnamic acids, such as caffeic acid, via an ester bond.[8-10] The most common chlorogenic acid is 5-O-caffeoylquinic acid (5-CQA; chlorogenic acid).[8, 9, 11] However, many other structural isomers are present in plants, such as 3-O-caffeoylquinic acid (3-CQA; neochlorogenic acid) and 4-O-caffeoylquinic acid (4-CQA; cryptochlorogenic acid) (Figure 1).[10] Along with these, diCQAs, triCQAs and a tetraCQA have been reported in literature.[8]

Chlorogenic acids are one of the most abundant classes of phenolics in the human diet,[9, 12] and have been purported to have numerous health benefits. For instance, it was demonstrated that they possess antioxidant,[13-16] anti-inflammatory[17] and anti-HIV properties[18] as well as the ability to inhibit carcinogenesis.[12, 19] In addition, chlorogenic acids have been reported to play an important role in food quality. In coffee, high levels of mono-caffeoylquinic acids are indicators of lower coffee quality while higher levels of di-caffeoylquinic acids were positively correlated with higher quality. [20]'[21] Chlorogenic acids are also prominent in fruit juices.[22] For example, 5-CQA is reported as the major phenolic found in both apple and pear juices.[2325] However, the exact structural identity of the various chlorogenic isomers in these juices has only been partially determined.[24, 25] In addition, chlorogenic acids are thermally labile, as such they can undergo structural changes under common food processing conditions such as canning, roasting and pasteurization.[26] Therefore, the ability to differentiate between various chlorogenic acids (Figure 1) and an understanding of their breakdown products is important for assessing both food quality and in estimating the health benefits of foods rich in these compounds.

Various analytical techniques have been developed for the separation and detection of chlorogenic acids, where the most widely employed method is reversed phase high performance liquid chromatography (RP-HPLC), typically coupled with photodiode array (PDA) detection.[3, 27] Another analytical method that has been used to confirm structural information about chlorogenic acids in a variety of food products, including apples, coffee beans and dried plums is HPLC coupled to mass spectrometry (MS).[28-30] MS is a superior platform for the analysis of phenolics due to its high sensitivity and selectivity. It allows for the identification and quantification of minor chlorogenic acids in a complex phenolic mixture.[27]

To fully utilize MS, an understanding of analyte dissociation patterns during tandem (MS/MS) and multi-stage $\left(\mathrm{MS}^{\mathrm{n}}\right)$ mass spectrometric analysis is required. The establishment of MS/MS fingerprints can be used for structural elucidations as well as for identifying unique product ions that can be used for targeted multiple reaction monitoring (MRM) quantitative analysis.[31, 32] The application of MS/MS analysis to a selection of chlorogenic acids and other 
closely related compounds employing ion trap mass spectrometers have been reported in the literature.[9, 28, 33-36] However, the reported work was primarily focused on the negative ion mode in which only few product ions were structurally identified. In addition, some of the reported work proposed the formation of multisite-radical product ions[33, 35], which is not probable during collision induced dissociation (CID)-MS/MS conditions. As such, there is an absence of universal MS/MS fragmentation patterns with well-rationalized structures for chlorogenic acids. In addition, only two product ions have been reported for chlorogenic acids during positive ionization, which indicate that there is still much work to be done in the elucidation of the MS/MS fragmentation pathways of chlorogenic acids.[30, 36, 37] Therefore, one of the goals of this research was to establish the MS/MS fragmentation pathways of three common mono-caffeoylquinic acid isomers (Figure 1) using both positive and negative ionization. The primary goal was to gain an understanding of how caffeoylquinic acids dissociate during CID-MS/MS analysis as well as to develop a method for the differentiation of chlorogenic acid isomers.

An additional goal was to separate these isomeric species within juice samples without the need for chromatographic separation. Due to the similarity in structures of the three isomers used in this study (Figure 1), we also employed differential ion mobility-MS/MS.[38] Ion mobility has been used to effectively separate structurally similar compounds, including isomers and chiral mixtures.[39, 40] Differential mobility devices are ideal in this type of analysis as ion subsets (ideally only containing one isomer) are continuously delivered to the mass spectrometer for an in-depth analysis. More critically, ion mobility linked to MS/MS can allow for the identification and quantification of structurally similar compounds without the need for tedious chromatographic separation.[39] Therefore, a second major goal of this research was to employ high field asymmetric waveform ion mobility spectrometry (FAIMS) to separate the three most common mono-caffeoylquinic acids (3-CQA, 4-CQA and 5-CQA) in commercial apple and pear juice samples.

\section{MATERIALS \& METHODS}

\section{Materials.}

Standards of 5-O-caffeoylquinic acid (chlorogenic acid; 5-CQA), 4-O-caffeoylquinic acid (cryptochlorogenic acid; 4-CQA) and 3-O-caffeoylquinic acid (neochlorogenic acid; 3-CQA) were purchased from Sigma-Aldrich Canada Ltd. (Oakville, ON, Canada). All standards were at least 95\% in purity. HPLC grade methanol was obtained from Fisher Scientific (Ottawa, ON, Canada). The water used throughout this study was from a Millipore Milli-Q water system (Millipore Corp., Milford, MA, USA). Commercial apple and pear juice concentrates were from China and the United States, respectively.

Stock solutions of the caffeoylquinic acids at a concentration of $1.0 \mathrm{mM}$ were prepared by dissolving the standards in $50 \%(\mathrm{v}: \mathrm{v})$ aqueous methanol. The standards were then syringe filtered (nylon, $0.2 \mu \mathrm{m}$ pore size, $13 \mathrm{~mm}$ diameter; Chromatographic Specialties, Brockville, ON, Canada) and stored at $-20^{\circ} \mathrm{C}$ until use.

\section{Mass Spectrometric Analysis.}

Mass spectrometric analysis of the caffeoylquinic acids was performed on three different MS platforms, in order to confirm reproducibility and the applicability of the developed methods 
Cite this article as : Willems, J., Khamis, M.M., Saeid, W.M., et al. Anal Chim Acta. 2016 Aug 24; 933:16474. Final publication is available at: http://dx.doi.org/10.1016/j.aca.2016.05.041.

across a variety of instruments. These included a triple quadrupole linear ion trap mass spectrometer (QqQ-LIT MS) and two different quadrupole orthogonal time-of-flight mass spectrometers (QqToF MS). All instruments were equipped with an electrospray ionization source (ESI). The experimental conditions of the sample (i.e. analyte concentration and solvent makeup) was optimized for each instrument as discussed below.

\section{Triple Quadrupole Linear Ion Trap Mass Spectrometry (QqQ-LIT MS).}

First stage tandem MS/MS and second generation MS/MS/MS $\left(\mathrm{MS}^{3}\right)$ experiments were performed using both a QTRAP 4000 LC/MS/MS system (Applied Biosystems, Foster City, CA, USA) and a hybrid triple quadrupole linear ion trap mass spectrometer (QqQ-LIT) equipped with a “Turbo V Ion Spray” ESI source.

Stock solutions of the individual caffeoylquinic acids were diluted 100x with $50 \%$ (v/v) aqueous methanol and infused directly into the ESI source using a model 11 Plus syringe pump (Harvard Apparatus, MA, USA) at a flow rate of $10 \mu \mathrm{L} / \mathrm{min}$. The declustering potential (DP) and collision energy (CE) were ramped and optimized to obtain the greatest number of product ions while the precursor ion remained abundant. Optimum CE values employed were $-20 \mathrm{eV}$ and +18 $\mathrm{eV}$ for sample analysis in the negative and positive ion modes, respectively. To assess if the MS response was proportional to analyte concentration, three different concentrations were tested, namely $10 \mu \mathrm{M}, 5 \mu \mathrm{M}$, and $2.5 \mu \mathrm{M}$.

\section{Electrospray-Quadrupole Orthogonal Time-of-Flight Mass Spectrometry (ESI-QqToF MS).}

The stock solutions of the three caffeoylquinic acids were diluted $10 \mathrm{x}$ with $50 \%(\mathrm{v} / \mathrm{v})$ aqueous methanol containing $0.15 \%$ formic acid. Samples were analyzed using both the positive and negative ionization modes on an API QSTAR XL MS/MS hybrid QqToF tandem mass spectrometer equipped with an ESI source (Applied Biosystems Inc., CA, USA). The DP was set at $80 \mathrm{~V}$ and sample solutions were infused into the ESI chamber (Turbo Ionspray source) by an integrated Harvard syringe pump (Harvard Apparatus, MA, USA) at a rate of $10 \mu \mathrm{L} / \mathrm{min}$ with the following parameters: spray chamber temperature $100^{\circ} \mathrm{C}$, needle voltage $5500 \mathrm{~V}$. Nitrogen was used as both the drying and ESI nebulizing gas. External calibration employing caesium iodide $(\mathrm{m} / \mathrm{z}$ 132.9054) and sex pheromone inhibitor iPD1 ( $\mathrm{m} / \mathrm{z}$ 829.5398) was used to ensure high mass accuracies and to minimize errors in mass measurements. Mass spectra were analyzed using the Analyst software. MS/MS analysis was performed in the negative and positive ion modes and the CEs were optimized to induce fragmentation while the precursor ion remained abundant; the final CEs were $-19 \mathrm{eV}$ and $+22 \mathrm{eV}$ in the negative and positive ion modes, respectively.

The same experiments were repeated using an Agilent 6550 iFunnel Q-TOF (Agilent Technologies, Mississauga, ON, Canada) system. Caffeoylquinic acid stock solutions were diluted 40x with 50\% aqueous methanol. Standards were infused, using an infusion pump (KD Scientific, Holliston, MA, USA) for enhanced reference mass delivery, Agilent Jet Stream (AJS) ESI source at a flow rate of $50 \mu \mathrm{L} / \mathrm{min}$. The ESI source was operated in both the negative and positive ion modes. Mass spectra were recorded in the range of 50-1,200 m/z at a rate of 2 spectra/s with an isolation width of $1.3 \mathrm{amu}$. Gas temperature, sheath gas flow and the nebulizer were set at $250{ }^{\circ} \mathrm{C}, 11 \mathrm{~L} / \mathrm{min}$ and $20 \mathrm{psi}$, respectively. The source VCap was set at $4000 \mathrm{~V}$ and the nozzle voltage at $500 \mathrm{~V}$ while the fragmentor and Octopole RF peak were set at $365 \mathrm{~V}$ and $750 \mathrm{~V}$, respectively. MS/MS spectra were acquired using a collision energy of $20 \mathrm{eV}$ in both the positive and negative ion modes. The system continually corrected any mass drifts by passing 
Cite this article as : Willems, J., Khamis, M.M., Saeid, W.M., et al. Anal Chim Acta. 2016 Aug 24; 933:16474. Final publication is available at: http://dx.doi.org/10.1016/j.aca.2016.05.041.

Agilent reference solutions (+ve mode ion: HP-0921, 922.009798 m/z; -ve mode ion: HP-0921TFA adduct, $1033.988109 \mathrm{~m} / \mathrm{z}$ ) through the reference nebulizer.

\section{Phenolic Isolation from Commercial Apple and Pear Juice.}

Phenolics were isolated from commercial apple and pear juice concentrates employing Amberlite XAD-16N resin (Sigma-Aldrich Canada Ltd., Oakville, ON).[41] The resin was hydrated in $50 \%(\mathrm{v} / \mathrm{v})$ aqueous methanol for 30 minutes before being transferred to a glass column $(8.0 \mathrm{~cm} \times 3.0 \mathrm{~cm})$ to produce a bed volume of approximately $55 \mathrm{~mL}$. The resin bed was pre-conditioned with $110 \mathrm{~mL}$ of water followed by $110 \mathrm{~mL} \mathrm{90 \%} \mathrm{(v/v)} \mathrm{aqueous} \mathrm{methanol} \mathrm{and} 110$ $\mathrm{mL}$ of water.

Juice samples were diluted to $11.5 \pm 0.1^{\circ}$ Brix for apple and $12.0 \pm 0.1^{\circ}$ Brix for pear juice (Auto Abbe Refractometer; Leica Inc., Buffalo, NY, USA) prior to phenolic isolation. Columns were loaded with $15 \mathrm{~mL}$ of appropriately diluted juice and then washed with $110 \mathrm{~mL}$ of water to elute water-soluble compounds. Fruit phenolics were eluted by washing with $110 \mathrm{~mL}$ of $70 \%(\mathrm{v} / \mathrm{v})$ aqueous methanol. The phenolic fractions were concentrated using a Büchi rotary evaporator (Flawil, Switzerland) and samples were freeze dried (Hetro Lab Equipment, Allerod, Denmark) in 12 x 32 mm glass vials (Chromatographic Specialties, Brockville, ON, Canada) and stored at $-18{ }^{\circ} \mathrm{C}$ until use. Separate Amberlite XAD-16N columns were used for each juice sample.

\section{High-field Asymmetric Waveform Ion Mobility Spectrometry (FAIMS)-Mass Spectrometric Analysis}

The three caffeoylquinic acids were analyzed using ESI-FAIMS-MS on a FAIMSequipped Thermo Fisher TSQ Vantage mass spectrometer (San Jose, CA). A modified FAIMS electrode set was employed, which enabled improved desolvation and higher electric field strengths to be achieved compared with the commercial FAIMS electrode set.[42] System setup was also modified to allow for the introduction of gas additives into the FAIMS gas flow as described previously.[43] Briefly, gas additives were introduced by teeing liquids into the gas line using an Agilent 1200 HPLC system (Mississauga, ON, CA). A mixing chamber was inserted between the tee and the FAIMS device to ensure a uniform gas composition and to prevent droplets from entering the FAIMS. The amount of gas additive present in the gas stream was calculated based on a molar ratio and expressed as a percentage.[43] For the spectra shown in this study, methanol was used as the gas additive and it was delivered to the gas stream at a rate of $0.175 \mathrm{~mL} / \mathrm{min}$ (into $5 \mathrm{~L} / \mathrm{min}$ nitrogen) resulting in a molar ratio of $2.1 \%$.

Caffeoylquinic acid standard solutions were prepared in 50\% methanol at a concentration of $10 \mu \mathrm{M}$ or in a mixture at a concentration of $3.3 \mu \mathrm{M}$. Phenolic isolates from apple and pear juices were prepared by adding $1.0 \mathrm{~mL}$ of $50 \%$ methanol to the freeze dried extracts with sonication for 10 minutes to ensure solubilisation. The solutions were then diluted 100 fold with 50\% methanol. Samples, infused using a Harvard Apparatus syringe pump at a flow rate of 10 $\mu \mathrm{L} / \mathrm{min}$, were diluted by teeing in a solvent of $0.1 \%$ formic acid in $50 \%$ methanol (delivered using an Agilent $1100 \mathrm{HPLC}$ system) to give a flow rate of $200 \mu \mathrm{L} / \mathrm{min}$ at the ESI needle tip. Ions were generated using negative ionization and MS detection in the multiple reaction monitoring (MRM) mode. The monitored precursor ion $\rightarrow$ product ion transitions for the acids were $\mathrm{m} / \mathrm{z} 353 \rightarrow \mathrm{m} / \mathrm{z}$ 191, $\mathrm{m} / \mathrm{z} 353 \rightarrow \mathrm{m} / \mathrm{z} 179$ and $\mathrm{m} / \mathrm{z} 353 \rightarrow \mathrm{m} / \mathrm{z}$ 173. The conditions were optimized as follows: capillary temperature of $275^{\circ} \mathrm{C}$, ion spray voltage of $-3300 \mathrm{~V}$, vaporizer 
Cite this article as : Willems, J., Khamis, M.M., Saeid, W.M., et al. Anal Chim Acta. 2016 Aug 24; 933:16474. Final publication is available at: http://dx.doi.org/10.1016/j.aca.2016.05.041.

temperature of $350{ }^{\circ} \mathrm{C}$, dispersion voltage of $-3500 \mathrm{~V}$, inner/outer electrode temperatures of $90 / 90{ }^{\circ} \mathrm{C}$, sheath gas of 60 and auxiliary gas of 10 and collision energy of $20 \mathrm{~V}$.

\section{RESULTS \& DISCUSSION}

\section{Single-stage MS analysis}

The ESI-MS full scan analysis of the mono-caffeoylquinic acid isomers gave the singly charged molecule for all three isomers in both the positive and negative ion modes, $[\mathrm{M}+\mathrm{H}]^{+}$and [M-H] , respectively. The theoretical $m / z$ values of the protonated and deprotonated species of the three isomers were 355.1024 and 353.0878, respectively. MS exact measurements were reported using the ESI-QqToF MS system (6550 iFunnel), which gave mass accuracies of less than 2 ppm for all three isomers. As these isomers, by definition, have the same molecular weights (and $\mathrm{m} / \mathrm{z}$ values), these measurements could not be used for any sort of differentiation between these compounds.

\section{Tandem MS analysis}

Chlorogenic acid (5-CQA) is the most common of the mono-caffeoylquinic acids found in nature and is also the most readily commercially available.[8, 10] Therefore, 5-CQA was used to optimize the MS conditions in this study (i.e., instrument parameters, collision energy and concentration). The MS/MS dissociation behaviour for all three isomers was studied using both negative and positive ionization on three different mass spectrometer systems. Generally, negative ionization has been reported to result in higher sensitivity for phenolics than positive ionization and therefore it is commonly used for caffeoylquinic acid MS/MS analysis.[44] Since MS/MS dissociation behavior using positive ionization has not been thoroughly addressed previously,[30, 37] it was also evaluated in this study.

MS/MS analysis in the positive ion mode

To the best of our knowledge, a thorough comparison of MS/MS spectra of monocaffeoylquinic acids produced using positive versus negative ionization has not been reported. The presence of the carboxylic acid functional group in each of these compounds makes them readily ionizable in negative ion mode resulting in good signal intensity. However, chlorogenic acids can also be readily ionized in positive ion mode due to the presence of multiple $\mathrm{OH}$ groups. Therefore, we performed dual MS/MS analysis giving insights into how these molecules dissociate under CID conditions in both ionization modes.

Figure 2 shows MS/MS spectra acquired with the QTRAP mass spectrometer and the proposed fragmentation pattern for the representative caffeoylquinic acid, 5-Omonocaffeoylquinic acid. All three mono-caffeoylquinic acid isomers followed the same MS/MS dissociation behavior as shown in Table 1, with a base peak observed at $m / z 163.1$ as well as a major product ion at $m / z 181.0$ which agrees well with published reports.[30, 37] However, no work has been presented that gives a detailed evaluation of the MS/MS dissociation behavior of chlorogenic acids using positive ionization, such as identifying the structures of the various observed product ions and rationalizing their fragmentation pathways.

The product ion at $\mathrm{m} / \mathrm{z} 181.0$ was identified as the caffeic acid portion of the molecule formed through the cleavage of the ester linkage between chlorogenic and quinic acid. It was anticipated that the ester linkage would be the primary location for dissociation in the gas phase 
Cite this article as : Willems, J., Khamis, M.M., Saeid, W.M., et al. Anal Chim Acta. 2016 Aug 24; 933:16474. Final publication is available at: http://dx.doi.org/10.1016/j.aca.2016.05.041.

as this bond is highly prone to hydrolysis. However, the product ion at $\mathrm{m} / \mathrm{z} 181.0$ was a minor ion as compared with the ion observed at $\mathrm{m} / \mathrm{z} 163.1$ in all three isomers. It is proposed that the production of the ion at $\mathrm{m} / \mathrm{z} 163.1$ was formed through water loss from caffeic acid with $\mathrm{m} / \mathrm{z}$ 181.0. This is supported by a MS ${ }^{3}$ experiment that showed that $\mathrm{m} / \mathrm{z} 163.1$ is formed from the ion at $\mathrm{m} / \mathrm{z} 181.0$ (Table 2A). The product ions observed at $\mathrm{m} / \mathrm{z} 144.9,135.1$ and 117.0 were all identified as being formed from $\mathrm{m} / \mathrm{z} 163.1$ and are likely formed through the subsequent elimination of water and carbon monoxide moieties, as illustrated in Figure 2. The formation of the product ion at $\mathrm{m} / \mathrm{z} 117.0$ from both $\mathrm{m} / \mathrm{z} 144.9$ and 135.1 was confirmed through $\mathrm{MS}^{3}$ experiments (Table 2A). As expected, conjugation within the structures of the observed product ions resulted in enhanced stability during CID-MS/MS analysis.

Similar to the formation of a product ion representing the caffeic acid portion, the product ion observed at $\mathrm{m} / \mathrm{z} 193.1$ was identified as being derived from the quinic acid portion of the molecule also formed through the cleavage of the ester linkage. When subjected to $\mathrm{MS}^{3}$, the observed 193.1 product ion dissociated into additional ions, namely the product ions observed at $\mathrm{m} / \mathrm{z}$ values of $175.0,157.3,147.0,139.1$ and 129.2 . The ions at $\mathrm{m} / \mathrm{z}$ values $175.0,157.3$ and 139.1 were formed through subsequent water losses from the ion observed at $m / z$ 193.1. Whereas, the product ions observed at $\mathrm{m} / \mathrm{z}$ values 147.0 and 129.2 originated from the ion observed at $\mathrm{m} / \mathrm{z} 175.0$ through: a) inner ring fragmentation with the neutral loss of an ethylene molecule; and b) the loss of a formic acid molecule, respectively. While these product ions were readily detected in 5-CQA they were not identified in either 3-CQA or 4-CQA (Table 1). However, the product ions observed for 5-CQA in the positive ion mode correlated well with those obtained in the negative ion mode, which will be discussed in the following section. Table 1 summarizes the product ions observed for each of the three mono-caffeoylquinic acid isomers.

Due to the similarity in the MS/MS profiles of the three isomers (Table 1) and the low abundance of some of the observed product ions, it was not feasible to reliably differentiate between these compounds in positive ion mode. However, if combined with chromatographic separation, the produced product ions can be used for the development of targeted LC-MRM quantification methods.[45-47]

\section{MS/MS analysis in negative ion mode}

Figure 3 shows a negative ion mode MS/MS spectrum and the proposed fragmentation pattern for a representative mono-caffeoylquinic acid, 4-O-monocaffeoylquinic acid. Unlike the results from the positive ion mode, all three isomers produced the same ions under MS/MS conditions in the negative ion mode. Structural assignment and the proposed MS/MS fragmentation pathway were confirmed by employing MS $^{3}$ experiments using ESI-QqQ-LIT (Table 2B).

All three mono-caffeoylquinic acid isomers analyzed showed the same product ions allowing for the determination of a generalized MS/MS fragmentation pathway. However, the relative abundances of the observed product ions varied among the different isomers as described in more detail below. In addition, all three of the MS systems showed the same general fragmentation patterns as well as relative abundances, with the only difference among them being sensitivity. That is, some of the minor product ions were only observable by ESI-QqQLIT. This was due to the trapping capability of the linear ion trap, allowing for the observation of minor product ions. However, all of the major product ions were observed in all three systems. 
Cite this article as : Willems, J., Khamis, M.M., Saeid, W.M., et al. Anal Chim Acta. 2016 Aug 24; 933:16474. Final publication is available at: http://dx.doi.org/10.1016/j.aca.2016.05.041.

The three major product ions detected in the negative ion mode were observed at $\mathrm{m} / \mathrm{z}$ $190.7,178.8$ and 172.6 . The product ion at $m / z 190.7$ was identified as quinic acid, which is formed by the cleavage of the ester bond between the quinic and caffeic acid moieties. This product ion was a major peak for all three isomers. The proposed structure agreed well with literature that reported the presence of the quinic acid product ion with the only variations being in the location of the charge.[28, 30,33] The abundance of this ion was not surprising as the ester bond is prone to cleavage during CID-MS/MS. The abundance of the quinic acid ion is likely explained by the presence of a carboxylic acid functional group that can be readily ionized in the negative ion mode. It should be noted that similar behavior has been observed in analogous compounds. For example, it was observed that chlorogenic acid lactones, where a lactone is formed between the carboxylic acid and a hydroxyl group on the quinic acid moiety, showed a major product ion corresponding to the quinic acid lactone (quinide).[9]

The quinic acid product ion ( $\mathrm{m} / \mathrm{z}$ 190.7) dissociated further under the CID conditions employed. The loss of a water molecule to form the product ion at $\mathrm{m} / \mathrm{z} 172.6$ is expected, as there are many potential locations for water loss due to the number of hydroxyl groups on the quinic acid moiety. As with the ion observed at $m / z$ 190.7, this structure agreed with those previously reported in the literature for both mono-caffeoylquinic acids as well as other related chlorogenic acids.[28, 30, 33]

The ion representing quinic acid ( $\mathrm{m} / \mathrm{z}$ 190.7) fragmented to yield the product ion at $\mathrm{m} / \mathrm{z}$ 127.1 via the concurrent losses of water and carbon dioxide moieties. Theoretically, this product ion could be formed from the ion observed at $\mathrm{m} / \mathrm{z}$ 172.6, via the loss of carbon dioxide, however no evidence of this mechanism was observed by $\mathrm{MS}^{3}$ experiments (Table 2B). In addition, the product ion at $\mathrm{m} / \mathrm{z} 127.1$ dissociated further to form the ion observed at $\mathrm{m} / \mathrm{z} 108.9$ through the loss of an additional water molecule. The proposed structure for the ion at $\mathrm{m} / \mathrm{z} 108.9$ consists of an aromatic ring after the loss of three water molecules with the subsequent formation of three double bonds.

Similarly, the product ion at $\mathrm{m} / \mathrm{z} 172.6$ was shown to lose a water molecule forming the ion observed at $\mathrm{m} / \mathrm{z} 155.0$, which subsequently lost either water or carbon dioxide to form the product ions observed at $\mathrm{m} / \mathrm{z} 137.0$ and 110.6 , respectively (Figure 3 ). Structures previously reported for the ions observed at $\mathrm{m} / \mathrm{z} 127.1$ and 110.6, were reported as those containing multiple radicals within the structure[33]. This is highly unlikely as a structure containing three radical sites on carbon within the same molecule would be unstable and would not be observed during ESI-CID-MS/MS.[48]

The product ion at $\mathrm{m} / \mathrm{z} 178.8$ was identified at the caffeic acid portion of the molecule (Figure 1). This fragment has been previously reported in literature for 5-CQA.[30] As well, other chlorogenic acids have been shown to undergo similar fragmentation behavior where the cinnamic acid is lost from the molecule under MS/MS analysis in negative ion mode.[9, 35] The ion at 178.8 loses a carbon dioxde moiety to produce the product ion observed at $\mathrm{m} / \mathrm{z} 134.8$.

Finally, a product ion at $\mathrm{m} / \mathrm{z} 161.0$ was observed in the negative ion mode for all three isomers. This product ion has been previously reported in literature.[9, 35] Interestingly, this ion

was not observed in any of the $\mathrm{MS}^{3}$ experiments, suggesting that it was derived directly from the deprotonated precursor ion and not from another product ion such as $\mathrm{m} / \mathrm{z} 178.8$, as might be speculated.

\section{Comparison between positive and negative ion modes}


Cite this article as : Willems, J., Khamis, M.M., Saeid, W.M., et al. Anal Chim Acta. 2016 Aug 24; 933:16474. Final publication is available at: http://dx.doi.org/10.1016/j.aca.2016.05.041.

Of interest are the similarities between the product ions observed in the positive and negative ion modes, with many of the ions differing by only two mass units (i.e., the two hydrogen difference between positive and negative ion modes). For example, both the positive and negative ion modes show the quinic acid product ion and subsequent product ions derived from quinic acid at $m / z$ 193/191, 175/173, 157/155, 137/135 and 129/127. In addition, the positive and negative ion modes also shared some of the caffeic acid-based product ions at $\mathrm{m} / \mathrm{z}$ $181 / 179$ and 163/161. This observation of complementary ions aids in the confirmation of the proposed structures, and are readily explained by the cleavage of the same bonds in these compounds in both the positive and negative ion modes. However, more product ions derived from the caffeic acid portion of the molecule were observed in positive ion mode (Figures 2 and 3), namely those at $m / z 144.9,135.1$ and 117.0. This may be due to the caffeic acid portion of the molecule being more likely to retain a charge in the positive ion mode, whereas the quinic acidrelated product ions would be more likely to retain a charge in negative ion mode, due to the presence of the carboxylic acid functional group. This was supported by the observation that quinic acid-related product ions showed higher abundances in negative ion mode when compared with the analogous ions observed in positive ion mode.

While some prior work has examined the fragmentation of mono-caffeoylquinic acids in negative ion mode, most of these focused only on the major product ions, such as $\mathrm{m} / \mathrm{z} 190.7$, 178.8 and 172.6. In addition, no comprehensive general MS/MS fingerprints showing the genesis and structures of all of the observed product ions of mono-caffeoylquinic acids has been published either in positive or negative ion modes.

Based on previous reports of the MS/MS dissociation behaviour of other chlorogenic acid compounds (e.g., chlorogenic acid lactones and diferuloylquinic acids) in negative ion mode[9, 28] other chlorogenic acids may also have similar positive ion mode MS/MS fragmentation to the mono-caffeoylquinic acids shown here. The generalized dissociation pathways shown in Figures 2 and 3 may allow for the identification of a variety of different chlorogenic acids in both the positive and negative ion modes.

\section{Differentiation of mono-caffeoylquinic acids by MS/MS}

While all three mono-caffeoylquinic acid isomers showed the same general MS/MS fragmentation behaviour, it is possible to differentiate among the three isomers in the negative ion mode. This statement is based on the relative abundances of the three major product ions, namely $\mathrm{m} / \mathrm{z}$ 190.7, 178.8 and 172.6 (Figure 4; Table 3) as follows: 5-CQA was identified by a major base peak at $\mathrm{m} / \mathrm{z} 190.7$ with relatively minor product ions at $\mathrm{m} / \mathrm{z} 178.8$ and 172.6 ; 3CQA's base peak was also at $m / z$ 190.7, but it was differentiated from 5-CQA through the presence of a relatively abundant peak at $\mathrm{m} / \mathrm{z} 178.8$; and 4-CQA was differentiated from the other two isomers by having a base peak at $\mathrm{m} / \mathrm{z} 172.6$ at collision energies ranging from -15 to $35 \mathrm{~V}$ (Figure 4). It was also found that there was concentration dependent MS/MS response for all isomers when three different analyte concentrations were tested using the Q-LIT instrument, namely $10 \mu \mathrm{M}, 5 \mu \mathrm{M}$, and $2.5 \mu \mathrm{M}$. For example, the ion count for the diagnostic ion observed at $\mathrm{m} / \mathrm{z} 190$ for the 3-CQA isomer was $7.5^{\mathrm{e} 5}, 3.2^{\mathrm{e}}$, and $1.4^{\mathrm{e} 5}$, respectively (data not shown), indicating a concentration-dependent MS/MS response.

The observed MS/MS patterns were confirmed by analyzing the three monocaffeoylquinic acid isomers on three different mass spectrometers under a variety of collision energies on different days. These experiments confirmed that the relative abundances of the three 
Cite this article as : Willems, J., Khamis, M.M., Saeid, W.M., et al. Anal Chim Acta. 2016 Aug 24; 933:16474. Final publication is available at: http://dx.doi.org/10.1016/j.aca.2016.05.041.

product ions as shown in Table 2 could be reliably used to differentiate between these isomers regardless of the mass spectrometer and range of collision energies employed. Therefore, we utilized this feature to aid in the optimization of the differential mobility settings so that the all three mono-caffeoylquinic acids could be separated in commercial pure apple and pear juices.

\section{Separation of the mono-caffeoylquinic acid isomers using FAIMS-MS/MS}

Previously, HPLC alone or in conjunction with MS was used to separate caffeoylquinic acid isomers.[45, 46] However, HPLC-based methods are tedious requiring a long run time that can exceed an hour; therefore, they are impractical for high throughput screening of a large number of samples. As such, it would be highly advantageous to develop new analytical methods that can benefit from the selectivity and specificity of a mass spectrometer without the need for HPLC separation.

FAIMS is a rapidly growing separation technology that has been successfully interfaced with MS for various applications.[39] In principle, ions generated by an ESI source, for example, are filtered based on their differences in mobility employing oscillating high and low electric fields that act perpendicular to ion motion[49] prior to their transmission to the MS analyzer. FAIMS-MS has been shown to be an effective tool for the separation of isobaric compounds in short periods of time.[39, 43, 49] Therefore, we explored the possibility of employing FAIMSMS/MS for the separation of mono-caffeoylquinic acids without the use of an HPLC. In combination with the isomer-specific MS/MS fragmentation pattern observed in the negative ion mode (Figure 4 and Table 3), the use of FAIMS can provide a method to identify and potentially quantify these compounds in complex samples containing a variety of phenolics.

Optimization of the FAIMS parameters was performed on commercial standards in order to obtain reproducible separation of these isomers. The effects of various FAIMS parameters on the resolution of the isomers were investigated sequentially including the magnitude of the dispersion voltage (DV), electrode temperature and carrier gas composition as well as its flow rate. Initially, standards were analyzed without the presence of a gas modifier (100\% nitrogen as the carrier gas). Under such conditions, standards eluted from the smallest to the largest CV values in the order of 4-CQA, 5-CQA and finally 3-CQA, where all three isomers eluted at positive CV values. However, significant overlap between 4-CQA and 5-CQA was observed (data not shown), and variation of the DV from -3500 to $-4000 \mathrm{~V}$ resulted in minimal improvement in their separation.

Previous research has shown that the addition of a gas modifier to the nitrogen stream can aid in analyte separation during FAIMS analysis, particularly for low molecular weight compounds.[43] In addition, it was shown that acetonitrile provided the best separation, as compared to other gas modifiers such as methanol, for a series of 15 compounds when analyzed by FAIMS-MS/MS.[43] Therefore, acetonitrile was used initially for the analysis of the monocaffeoylqinic acid isomers. The addition of acetonitrile afforded the separation of the three isomers without affecting the elution order. Increasing the flow rate of acetonitrile from 0.050 $\mathrm{mL} / \mathrm{min}$ to $0.150 \mathrm{~mL} / \mathrm{min}$ resulted in a gradual improvement in isomer resolution that eventually deteriorated at a flow rate of $0.200 \mathrm{~mL} / \mathrm{min}$. Therefore, $0.150 \mathrm{~mL} / \mathrm{min}$ was chosen as the optimum flow rate. While the use of acetonitrile allowed for the separation of these monocaffeoylquinic acids, it also resulted in the appearance of a small secondary peak for each standard (data not shown). These secondary peaks are likely dimers, multimers or adducts formed with acetonitrile that decompose to monomers upon their introduction to the mass 
Cite this article as : Willems, J., Khamis, M.M., Saeid, W.M., et al. Anal Chim Acta. 2016 Aug 24; 933:16474. Final publication is available at: http://dx.doi.org/10.1016/j.aca.2016.05.041.

spectrometer.[49] Unfortunately, these secondary peaks overlapped with the main peaks of other isomers. Varying the DV values from -3300 to -3700 V did not improve the separation between the secondary peak of 4-CQA and the main peak of 5-CQA. Therefore, the gas modifier was switched from acetonitrile to methanol.

When methanol was used as the modifier gas, a single peak was observed for each standard (Fig 5A). In addition, the initial experiments exhibited significantly enhanced resolution in comparison with the optimized method using acetonitrile as the gas modifier. Near baseline resolution was achieved upon the optimization of the methanol flow rate at $0.175 \mathrm{ml} / \mathrm{min}$ and a DV value of -3500 V. Figure 5 A shows the optimum separation of the three standards, where 4CQA elutes at a CV value of 5.8 V, 5-CQA at 8.8 V and 3-CQA at $16.9 \mathrm{~V}$ under the optimized experimental conditions. Identification of each isomer was based on the established CV values combined with the diagnostic MS/MS behaviour discussed previously (Table 3). During ESIFAIMS-MS analysis, the three diagnostic product ions were monitored (i.e., $\mathrm{m} / \mathrm{z} 173,179$ and 191) and their abundances are represented as the solid, dotted and dashed lines in Figure 5, respectively. Each mono-caffeoylquinic acid can be identified by its unique product ion ratios as shown in Table 3 and Figure 4. For example, 5-CQA could be readily identified by its CV value of $8.8 \mathrm{~V}$ along with the large abundance of the $\mathrm{m} / \mathrm{z} 191$ product ion (dashed line, Figure $5 \mathrm{~A}$ ) and minimal amounts of either the $\mathrm{m} / \mathrm{z} 179$ or 173 ions (dotted and solid lines, respectively). The other two isomers were identified using the same approach, combining their differential ion mobility data with MS/MS ion intensity. Each approach alone was not sufficient for the absolute identification of the target isomers within juices. However, the combination of FAIMS with MS/MS afforded the identification of the three mono-caffeoylquinic acids in complex mixtures.

In addition to the gas modifier and DV values, the influence of electrode temperature on the resolution of the isomers was also evaluated. In these experiments, the temperatures of the inner and outer electrodes were varied synchronously from 55 to $110^{\circ} \mathrm{C}$, and the temperature of the outer electrode was held constant at $90^{\circ} \mathrm{C}$ and the temperature of the inner electrode was varied to produce gradients of -20 to $+5{ }^{\circ} \mathrm{C}$. It was found that increasing the temperature of both electrodes simultaneously resulted in significant improvement in the separation of the isomers. Similar improvement was noted when increasing the inner electrode temperature while maintaining the outer one at $90^{\circ} \mathrm{C}$. However, increasing the temperature above $90^{\circ} \mathrm{C}$ resulted in a remarkable decrease in the signal intensity with no further separation benefits. Therefore, the electrodes' temperature was fixed at $90^{\circ} \mathrm{C}$.

To demonstrate the use of FAIMS-MS/MS for the separation of mono-caffeoylquinic acids in real samples, commercial apple and pear juices were analyzed employing the optimized conditions. These samples were selected as they are known to contain a variety of phenolics[23, 24] that may interfere with the separation and detection of mono-caffeoylquinic acids. Initially, the juices were infused into the system without any prior sample preparation apart from dilution with water and filtration. However, the high carbohydrate content of these products ( $>95 \%$ of the total soluble solids)[50] interfered with the analysis causing strong ion suppression. Therefore, each juice was extracted as described[41] to separate the phenolics from carbohydrates. Once the carbohydrates were removed, clear CV spectra were obtained for each sample (Figures $5 \mathrm{~B}$ and C).

The apple juice sample contained all three of the mono-caffeoylquinic acid isomers, where 5-CQA was the major peak (Figure 5B). This result agreed with literature as 5-CQA 
Cite this article as : Willems, J., Khamis, M.M., Saeid, W.M., et al. Anal Chim Acta. 2016 Aug 24; 933:16474. Final publication is available at: http://dx.doi.org/10.1016/j.aca.2016.05.041.

(chlorogenic acid) has been reported to be the major phenolic found in apple products and the presence of other chlorogenic acids have also been noted.[24] However, the peak corresponding to 4-CQA isomer did not follow the exact pattern as shown in the standards in terms of ion intensities. Major product ions at m/z 191 and 173 were observed while 179 was present at lower abundance. This deviates from the pattern established using the standards (Figure 5A). Most likely, the observed peak, corresponding to 4CQA in Figure 5B is a mixture of 4-CQA and other mono-caffeoylquinic acid isomers reported in the literature, such as 1-caffeoylquinic acid or one of the cis mono-caffeoylquinic acids [51].

In the case of pear, 5-CQA has also been reported to be a major phenolic [51] supporting our findings that showed a major 5-CQA peak as well as a smaller 3-CQA peak (Figure 5C) in this juice. In the case of pear, a compound was observed that eluted at the same CV value as 4CQA with a $[\mathrm{M}-\mathrm{H}]^{-} \mathrm{m} / \mathrm{z}$ of 353 . However, its fragmentation pattern did not match that of 4CQA as it had a major product ion at $m / z 191$ (dashed line, Figure 5 C) with minor product ions at $m / z 179$ and $m / z$ 173. Therefore, this compound is not 4-CQA. It is most probably another mono-caffeoylquinic acid isomer such as 1-caffeoylquinic acid or one of the cis monocaffeoylquinic acids which have been recently reported to be found in various parts of pear fruit and leaves.[51]

Previously, phenolic profiling has been used as a method to detect adulteration in fruit based products.[2, 7] Therefore, the presence or absence of certain mono-caffeoylquinic acids, as determined by FAIMS-MS, may also be beneficial for authenticity analysis. For example, the presence of 4-CQA in juice claiming to be $100 \%$ pear may be indicative of the presence of undeclared apple juice. However, further work would need to be performed in order to determine the robustness of such methods for the detection of juice-to-juice adulteration.

From the aforementioned results, it can be deemed that ESI-FAIMS-MS/MS acts as a two-dimensional analytical platform that allows for the separation and identification of monocaffeoylquinic acid isomers in apple and pear juice samples without the need for time consuming HPLC separation. The short acquisition time (less than 1 min) suggests the potential suitability of the method to handle high volumes of samples typically observed in a food quality control laboratory in a timely fashion.

\section{CONCLUSION}

Generalized MS/MS fragmentation behavior was developed for mono-caffeoylquinic acids in both the positive and negative ion modes and the similarities and differences between the two modes were evaluated. Unique diagnostic product ions were identified that can be used in any future targeted analysis for either identification or quantification purposes. Interestingly, the three positional isomers were differentiated based on the MS/MS data in negative ion modes allowing for the development of a fast FAIMS-MS/MS identification method. A rapid ( $<1 \mathrm{~min}$ ) method for the separation and identification of these compounds in complex juice samples employing ESI-FAIMS-MS/MS was developed. The method allowed for the separation of the three isomers without the need for HPLC separation. We will utilize FAIMS-MS/MS to develop targeted quantification methods so that we can determine the amounts of each isomer within juice samples. This research lends itself well to further developments, such as authenticity analysis of fruit juices. 
Cite this article as: Willems, J., Khamis, M.M., Saeid, W.M., et al. Anal Chim Acta. 2016 Aug 24; 933:16474. Final publication is available at: http://dx.doi.org/10.1016/j.aca.2016.05.041.

Acknowledgements: The authors acknowledge the technical help provided by Dr. Paulos Chumala, and Mr. Ken Toms for their assistance in processing samples with the Agilent 6550 iFunnel Q-TOF and QSTAR systems, respectively. Ms. Deborah Michel for her technical help with the QTRAP system. The 4000 QTRAP LC/MS/MS and the Agilent 6550 iFunnel Q-TOF systems were acquired via Canada Foundation for Innovation (CFI) grants. Thermo Fisher for the use of the FAIMS enabled TSQ Vantage as part of a collaboration between the University of Saskatchewan and Thermo Fisher Scientific 
Cite this article as : Willems, J., Khamis, M.M., Saeid, W.M., et al. Anal Chim Acta. 2016 Aug 24; 933:16474. Final publication is available at: http://dx.doi.org/10.1016/j.aca.2016.05.041.

\section{References:}

[1] M. Friedman, H.S. Jürgens, Effect of $\mathrm{pH}$ on the stability of plant phenolic compounds, Journal of Agricultural and Food Chemistry, 48 (2000) 2101-2110.

[2] B. Fernandez de Simon, J. Perez-Ilzarbe, T. Hernandez, C. Gomez-Cordoves, I. Estrella, Importance of phenolic compounds for the characterization of fruit juices, Journal of Agricultural and Food Chemistry, 40 (1992) 1531-1535.

[3] F. Shahidi, M. Naczk, Phenolics in food and nutraceuticals, CRC press2003.

[4] J. Dai, R.J. Mumper, Plant phenolics: extraction, analysis and their antioxidant and anticancer properties, Molecules, 15 (2010) 7313-7352.

[5] B. Nayak, R.H. Liu, J.M. Tang, Effect of Processing on Phenolic Antioxidants of Fruits, Vegetables, and Grains-A Review, Crit Rev Food Sci, 55 (2015) 887-918.

[6] V. Lattanzio, Phenolic Compounds: Introduction, in: K.G. Ramawat, J.M. Mérillon (Eds.) Natural products - Phytochemistry, Botany and Metabolism of Alkaloids, Phenolics and Terpenes, SpringerVerlag Berlin Heidelberg2013, pp. 1543-1580.

[7] A. Versari, S. Biesenbruch, D. Barbanti, P. Farnell, Adulteration of fruit juices: dihydrochalcones as quality markers for apple juice identification, LWT-Food Science and Technology, 30 (1997) 585-589.

[8] M.N. Clifford, Chlorogenic acids and other cinnamates-nature, occurrence, dietary burden, absorption and metabolism, Journal of the Science of Food and Agriculture, 80 (2000) 1033-1043.

[9] R. Jaiswal, M.F. Matei, F. Ullrich, N. Kuhnert, How to distinguish between cinnamoylshikimate esters and chlorogenic acid lactones by liquid chromatography-tandem mass spectrometry, Journal of Mass Spectrometry, 46 (2011) 933-942.

[10] R. Upadhyay, L.J. Mohan Rao, An outlook on chlorogenic acids-occurrence, chemistry, technology, and biological activities, Critical reviews in food science and nutrition, 53 (2013) 968-984.

[11] C. IUPAC, I.I. CBN, The nomenclature of cyclitols, Eur. J. Biochem, 5 (1968) 1-12.

[12] R. Feng, Y. Lu, L.L. Bowman, Y. Qian, V. Castranova, M. Ding, Inhibition of activator protein-1, NF-KB, and MAPKs and induction of phase 2 detoxifying enzyme activity by chlorogenic acid, Journal of Biological Chemistry, 280 (2005) 27888-27895.

[13] Y. Kono, K. Kobayashi, S. Tagawa, K. Adachi, A. Ueda, Y. Sawa, H. Shibata, Antioxidant activity of polyphenolics in diets: rate constants of reactions of chlorogenic acid and caffeic acid with reactive species of oxygen and nitrogen, Biochimica et Biophysica Acta (BBA)-General Subjects, 1335 (1997) 335342.

[14] M.-H. Kweon, H.-J. Hwang, H.-C. Sung, Identification and antioxidant activity of novel chlorogenic acid derivatives from bamboo (Phyllostachys edulis), Journal of Agricultural and Food Chemistry, 49 (2001) 4646-4655.

[15] N. Nakatani, S.-i. Kayano, H. Kikuzaki, K. Sumino, K. Katagiri, T. Mitani, Identification, Quantitative Determination, and Antioxidative Activities of Chlorogenic Acid Isomers in Prune (Prunus d omestica L.), Journal of Agricultural and Food Chemistry, 48 (2000) 5512-5516.

[16] C.A. Rice-Evans, N.J. Miller, G. Paganga, Structure-antioxidant activity relationships of flavonoids and phenolic acids, Free radical biology and medicine, 20 (1996) 933-956. 
Cite this article as : Willems, J., Khamis, M.M., Saeid, W.M., et al. Anal Chim Acta. 2016 Aug 24; 933:16474. Final publication is available at: http://dx.doi.org/10.1016/j.aca.2016.05.041.

[17] M.D. Dos Santos, M.C. Almeida, N.P. Lopes, G.E.P. De Souza, Evaluation of the anti-inflammatory, analgesic and antipyretic activities of the natural polyphenol chlorogenic acid, Biological and Pharmaceutical Bulletin, 29 (2006) 2236-2240.

[18] B. McDougall, P.J. King, B.W. Wu, Z. Hostomsky, M.G. Reinecke, W.E. Robinson, Dicaffeoylquinic and dicaffeoyltartaric acids are selective inhibitors of human immunodeficiency virus type 1 integrase, Antimicrobial Agents and Chemotherapy, 42 (1998) 140-146.

[19] H. Mori, T. Tanaka, H. Shima, T. Kuniyasu, M. Takahashi, Inhibitory effect of chlorogenic acid on methylazoxymethanol acetate-induced carcinogenesis in large intestine and liver of hamsters, Cancer letters, 30 (1986) 49-54.

[20] M.N. Clifford, Chlorogenic acids-their complex nature and routine determination in coffee beans, Food Chemistry, 4 (1979) 63-71.

[21] A. Farah, M. Monteiro, V. Calado, A. Franca, L. Trugo, Correlation between cup quality and chemical attributes of Brazilian coffee, Food Chemistry, 98 (2006) 373-380.

[22] M.N. Clifford, Chlorogenic acids and other cinnamates-nature, occurrence and dietary burden', Journal of the Science of Food and Agriculture, 79 (1999) 362-372.

[23] G.A. Spanos, R.E. Wrolstad, Influence of variety, maturity, processing and storage on the phenolic composition of pear juice, Journal of Agricultural and Food Chemistry, 38 (1990) 817-824.

[24] G.A. Spanos, R.E. Wrolstad, D.A. Heatherbell, Influence of processing and storage on the phenolic composition of apple juice, Journal of Agricultural and Food Chemistry, 38 (1990) 1572-1579.

[25] T. Cui, K. Nakamura, L. Ma, J.-Z. Li, H. Kayahara, Analyses of arbutin and chlorogenic acid, the major phenolic constituents in oriental pear, Journal of agricultural and food chemistry, 53 (2005) 3882-3887.

[26] R. Jaiswal, M.F. Matei, A. Golon, M. Witt, N. Kuhnert, Understanding the fate of chlorogenic acids in coffee roasting using mass spectrometry based targeted and non-targeted analytical strategies, Food \& function, 3 (2012) 976-984.

[27] I. Ignat, I. Volf, V.I. Popa, Analytical Methods of Phenolic Compounds, Natural Products, Springer2013, pp. 2061-2092.

[28] M.N. Clifford, S. Knight, B. Surucu, N. Kuhnert, Characterization by LC-MS $n$ of four new classes of chlorogenic acids in green coffee beans: dimethoxycinnamoylquinic acids, diferuloylquinic acids, caffeoyl-dimethoxycinnamoylquinic acids, and feruloyl-dimethoxycinnamoylquinic acids, Journal of Agricultural and Food Chemistry, 54 (2006) 1957-1969.

[29] S.C. Marks, W. Mullen, A. Crozier, Flavonoid and chlorogenic acid profiles of English cider apples, Journal of the Science of Food and Agriculture, 87 (2007) 719-728.

[30] N. Fang, S. Yu, R.L. Prior, LC/MS/MS characterization of phenolic constituents in dried plums, Journal of Agricultural and Food Chemistry, 50 (2002) 3579-3585.

[31] J. Buse, I. Badea, R.E. Verrall, A. El-Aneed, Tandem mass spectrometric analysis of novel diquaternary ammonium gemini surfactants and their bromide adducts in electrospray-positive ion mode ionization, Journal of Mass Spectrometry, 46 (2011) 1060-1070.

[32] H. Awad, U. Das, J. Dimmock, A. El-Aneed, Establishment of tandem mass spectrometric fingerprint of novel antineoplastic curcumin analogues using electrospray ionization, Rapid Commun. Mass Spectrom, 29 (2015) 1-10. 
Cite this article as : Willems, J., Khamis, M.M., Saeid, W.M., et al. Anal Chim Acta. 2016 Aug 24; 933:16474. Final publication is available at: http://dx.doi.org/10.1016/j.aca.2016.05.041.

[33] M.N. Clifford, K.L. Johnston, S. Knight, N. Kuhnert, Hierarchical scheme for LC-MS $n$ identification of chlorogenic acids, Journal of Agricultural and Food Chemistry, 51 (2003) 2900-2911.

[34] M.N. Clifford, S. Knight, N. Kuhnert, Discriminating between the six isomers of dicaffeoylquinic acid by LC-MS n, Journal of Agricultural and Food Chemistry, 53 (2005) 3821-3832.

[35] R. Jaiswal, T. Sovdat, F. Vivan, N. Kuhnert, Profiling and Characterization by LC-MS n of the Chlorogenic Acids and Hydroxycinnamoylshikimate Esters in Maté (Ilex paraguariensis) ${ }^{\dagger}$, Journal of Agricultural and Food Chemistry, 58 (2010) 5471-5484.

[36] K. Schram, P. Miketova, J. Slanina, O. Humpa, E. Taborska, Mass spectrometry of 1, 3-and 1, 5dicaffeoylquinic acids, Journal of mass spectrometry, 39 (2004) 384-395.

[37] A. Sakushima, S. Hisada, S. Nishibe, H. Brandenderger, Application of fast atom bombardment mass spectrometry to chlorogenic acids, Phytochemistry, 24 (1985) 325-328.

[38] G. Verbeck, B. Ruotolo, H. Sawyer, K. Gillig, D. Russell, A fundamental introduction to ion mobility mass spectrometry applied to the analysis of biomolecules, Journal of biomolecular techniques: JBT, 13 (2002) 56.

[39] A.B. Kanu, P. Dwivedi, M. Tam, L. Matz, H.H. Hill, Ion mobility-mass spectrometry, Journal of Mass Spectrometry, 43 (2008) 1-22.

[40] P. Dwivedi, C. Wu, L.M. Matz, B.H. Clowers, W.F. Siems, H.H. Hill, Gas-phase chiral separations by ion mobility spectrometry, Analytical chemistry, 78 (2006) 8200-8206.

[41] R.C. GREEN, Physicochemical properties and phenolic composition of selected Saskatchewan fruits: buffaloberry, chokecherry and sea buckthorn, University of Saskatchewan Saskatoon, 2007.

[42] S. Prasad, M.W. Belford, J.-J. Dunyach, R.W. Purves, On an aerodynamic mechanism to enhance ion transmission and sensitivity of FAIMS for nano-electrospray ionization-mass spectrometry, Journal of The American Society for Mass Spectrometry, 25 (2014) 2143-2153.

[43] R.W. Purves, A.R. Ozog, S.J. Ambrose, S. Prasad, M. Belford, J.-J. Dunyach, Using gas modifiers to significantly improve sensitivity and selectivity in a cylindrical FAIMS device, Journal of the American Society for Mass Spectrometry, 25 (2014) 1274-1284.

[44] F. Cuyckens, M. Claeys, Mass spectrometry in the structural analysis of flavonoids, Journal of Mass Spectrometry, 39 (2004) 1-15.

[45] U. Vrhovsek, D. Masuero, M. Gasperotti, P. Franceschi, L. Caputi, R. Viola, F. Mattivi, A versatile targeted metabolomics method for the rapid quantification of multiple classes of phenolics in fruits and beverages, Journal of agricultural and food chemistry, 60 (2012) 8831-8840.

[46] P. Andrade, A. Carvalho, R. Seabra, M. Ferreira, A previous study of phenolic profiles of quince, pear, and apple purees by HPLC diode array detection for the evaluation of quince puree genuineness, Journal of Agricultural and Food Chemistry, 46 (1998) 968-972.

[47] D. Orčić, M. Francišković, K. Bekvalac, E. Svirčev, I. Beara, M. Lesjak, N. Mimica-Dukić, Quantitative determination of plant phenolics in Urtica dioica extracts by high-performance liquid chromatography coupled with tandem mass spectrometric detection, Food chemistry, 143 (2014) 48-53.

[48] N.B. Cech, C.G. Enke, Practical implications of some recent studies in electrospray ionization fundamentals, Mass Spectrometry Reviews, 20 (2001) 362-387. 
Cite this article as: Willems, J., Khamis, M.M., Saeid, W.M., et al. Anal Chim Acta. 2016 Aug 24; 933:16474. Final publication is available at: http://dx.doi.org/10.1016/j.aca.2016.05.041.

[49] D.G. Beach, J.E. Melanson, R.W. Purves, Analysis of paralytic shellfish toxins using high-field asymmetric waveform ion mobility spectrometry with liquid chromatography-mass spectrometry, Analytical and bioanalytical chemistry, 407 (2015) 2473-2484.

[50] J.L. Willems, N.H. Low, Authenticity Analysis of Pear Juice Employing Chromatographic Fingerprinting, Journal of agricultural and food chemistry, 62 (2014) 11737-11747.

[51] J. Kolniak-Ostek, J. Oszmiański, Characterization of phenolic compounds in different anatomical pear (Pyrus communis L.) parts by ultra-performance liquid chromatography photodiode detectorquadrupole/time of flight-mass spectrometry (UPLC-PDA-Q/TOF-MS), International Journal of Mass Spectrometry, 392 (2015) 154-163. 
Cite this article as: Willems, J., Khamis, M.M., Saeid, W.M., et al. Anal Chim Acta. 2016 Aug 24; 933:164-

74. Final publication is available at: http://dx.doi.org/10.1016/j.aca.2016.05.041.

\section{FIGURE CAPTIONS}

Figure 1. Structures and nomenclature of the common mono-caffeoylquinic acids and their building blocks, quinic acid and caffeic acid (trivial names in brackets).

Figure 2. The proposed generalized positive ion mode MS/MS fragmentation pattern and ESIQqQ-LIT MS/MS spectrum of 5-CQA as a representative spectrum.

Figure 3. The proposed generalized negative ion mode MS/MS fragmentation pattern and representative ESI-QqQ-LIT MS/MS spectrum of 4-CQA.

Figure 4. Negative mode mass spectrums of 5-CQA (A), 4-CQA (B) and 3-CQA (C) obtained with the 6550 iFunnel QTOF.

Figure 5. CV spectra for the mixed mono-caffeoylquinic acid isomer standards (A), and commercial apple (B) and pear juices (C). 
Cite this article as: Willems, J., Khamis, M.M., Saeid, W.M., et al. Anal Chim Acta. 2016 Aug 24; 933:16474. Final publication is available at: http://dx.doi.org/10.1016/j.aca.2016.05.041.

\section{TABLE CAPTIONS}

Table 1. Product ions of mono-caffeoylquinic acid isomers observed in the positive ion mode during CID-MS/MS analysis.

Table 2. Tabulated $\mathrm{MS}^{3}$ experiments in the positive ion mode (A) and the negative ion mode (B) for the monocaffeoylquinic acids.

Table 3. Major MS/MS product ions at $m / z$ 191, 179 and 173 (counts $>5.0 \times 10^{4}$ by 6550 iFunnel QTOF) used for isomer identification. 
Cite this article as : Willems, J., Khamis, M.M., Saeid, W.M., et al. Anal Chim Acta. 2016 Aug 24; 933:16474. Final publication is available at: http://dx.doi.org/10.1016/j.aca.2016.05.041.<smiles>O=C(O)C1CC(O)C(O)C(O)CC1(O)C(=O)O</smiles>

Quinic acid<smiles>O=C(O)/C=C/c1ccc(O)c(O)c1</smiles>

Caffeic acid<smiles>O=C(O)C1CC(O)C(O)C(O)CC(O)(C(=O)O)C1O</smiles>
(Chlorogenic acid)<smiles>CC(=O)OOC(=O)OOC(=O)OC1CCC(O)(C(=O)O)CC(O)C1OC(=O)C=Cc1ccc(O)c(O)c1</smiles>

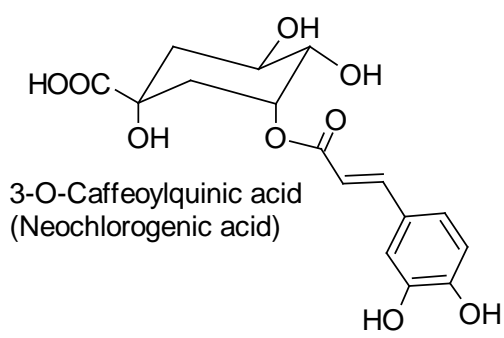

Figure 1. Structures and nomenclature of the common mono-caffeoylquinic acids and their building blocks, quinic acid and caffeic acid (trivial names in brackets). 
Cite this article as : Willems, J., Khamis, M.M., Saeid, W.M., et al. Anal Chim Acta. 2016 Aug 24; 933:164-74. Final publication is available at: http://dx.doi.org/10.1016/j.aca.2016.05.041.

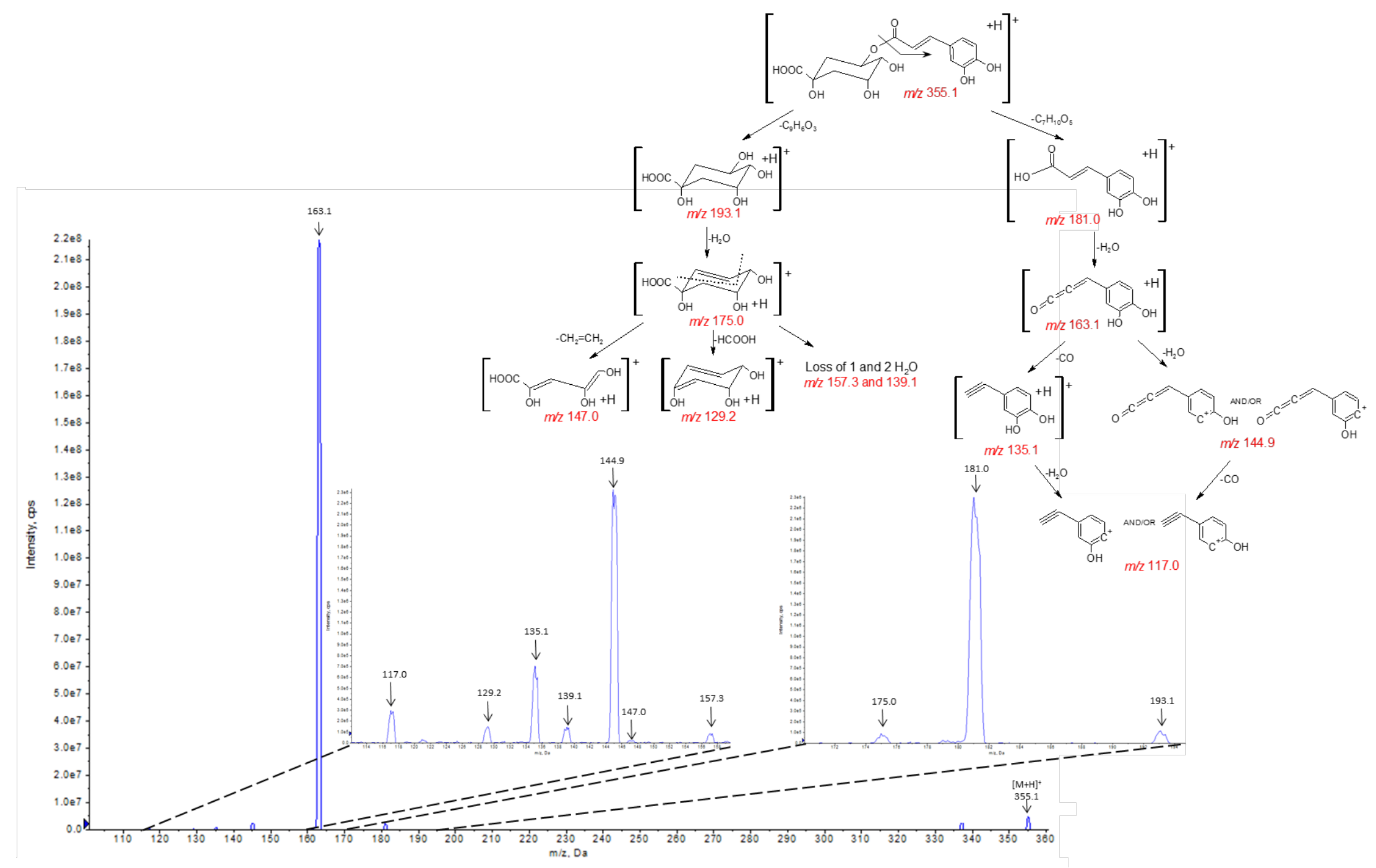

Figure 2. The proposed generalized positive ion mode MS/MS fragmentation pattern and ESI-QqQ-LIT MS/MS spectrum of 5-CQA as a representative spectrum. 
Cite this article as : Willems, J., Khamis, M.M., Saeid, W.M., et al. Anal Chim Acta. 2016 Aug 24; 933:164-

74. Final publication is available at: http://dx.doi.org/10.1016/j.aca.2016.05.041.

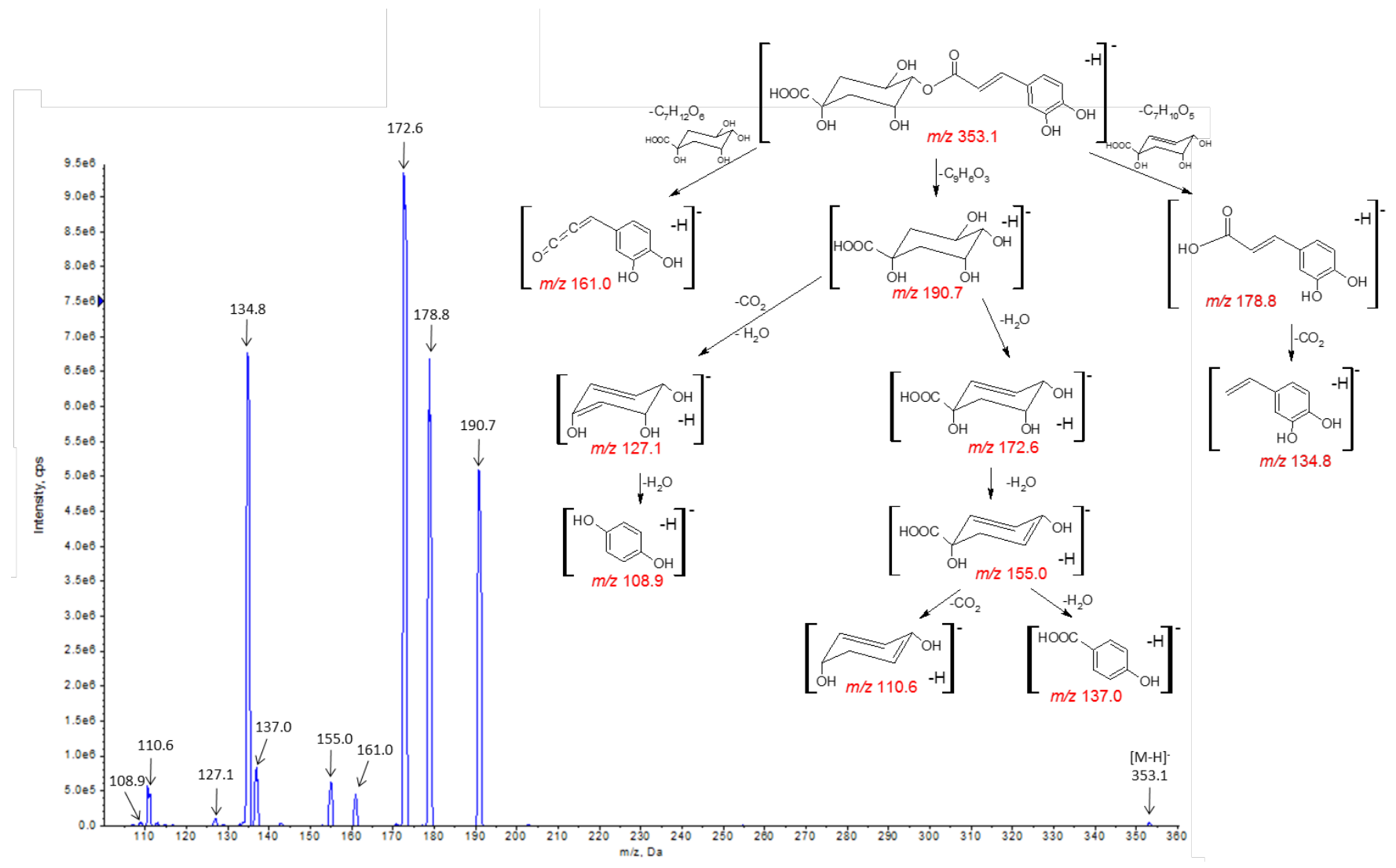

Figure 3. The proposed generalized negative ion mode MS/MS fragmentation pattern and ESIQqQ-LIT MS/MS spectrum of 4-CQA. 
Cite this article as : Willems, J., Khamis, M.M., Saeid, W.M., et al. Anal Chim Acta. 2016 Aug 24; 933:16474. Final publication is available at: http://dx.doi.org/10.1016/j.aca.2016.05.041.

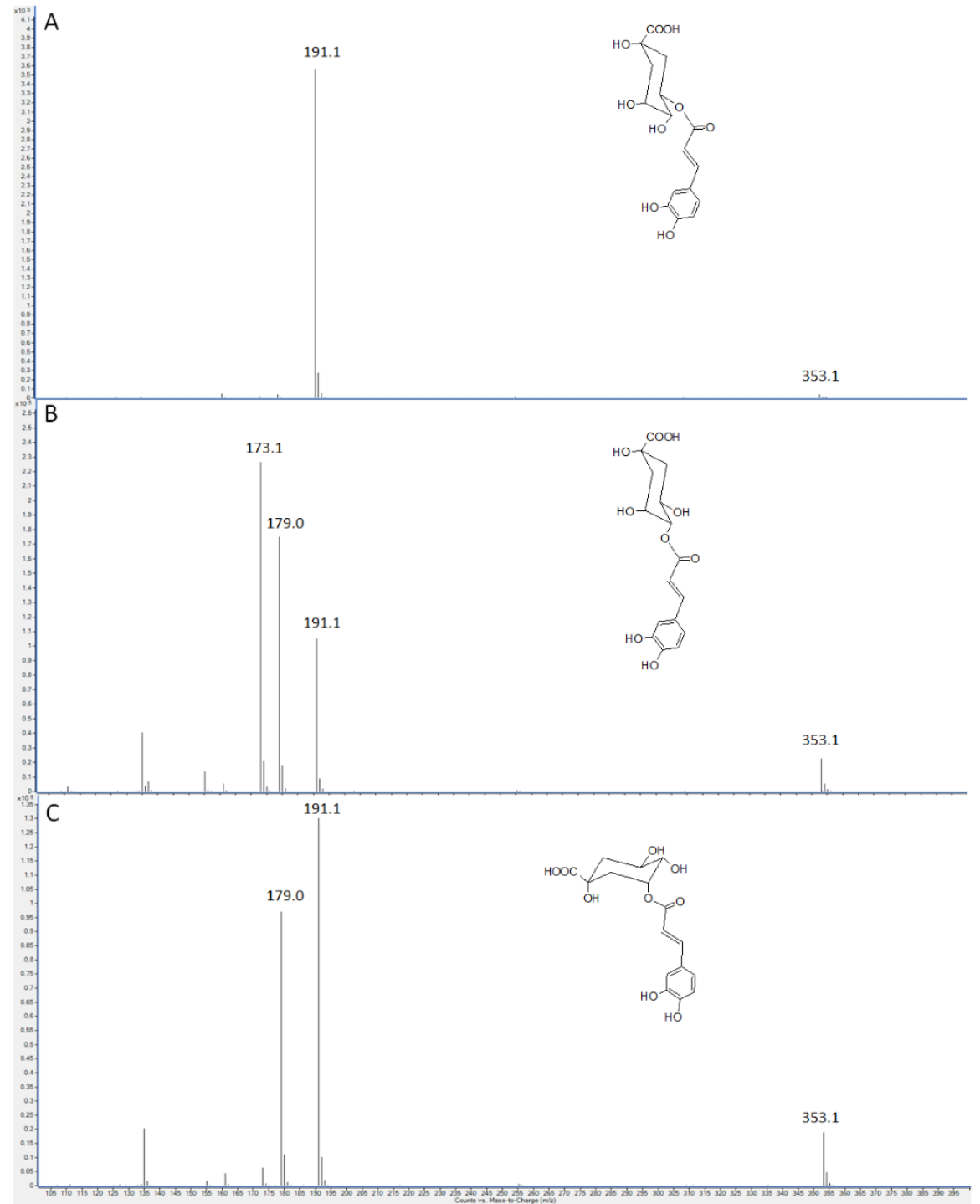

Figure 4. Negative mode mass spectra of 5-CQA (A), 4-CQA (B) and 3-CQA (C) obtained with the 6550 iFunnel QTOF. 
Cite this article as : Willems, J., Khamis, M.M., Saeid, W.M., et al. Anal Chim Acta. 2016 Aug 24; 933:16474. Final publication is available at: http://dx.doi.org/10.1016/j.aca.2016.05.041.
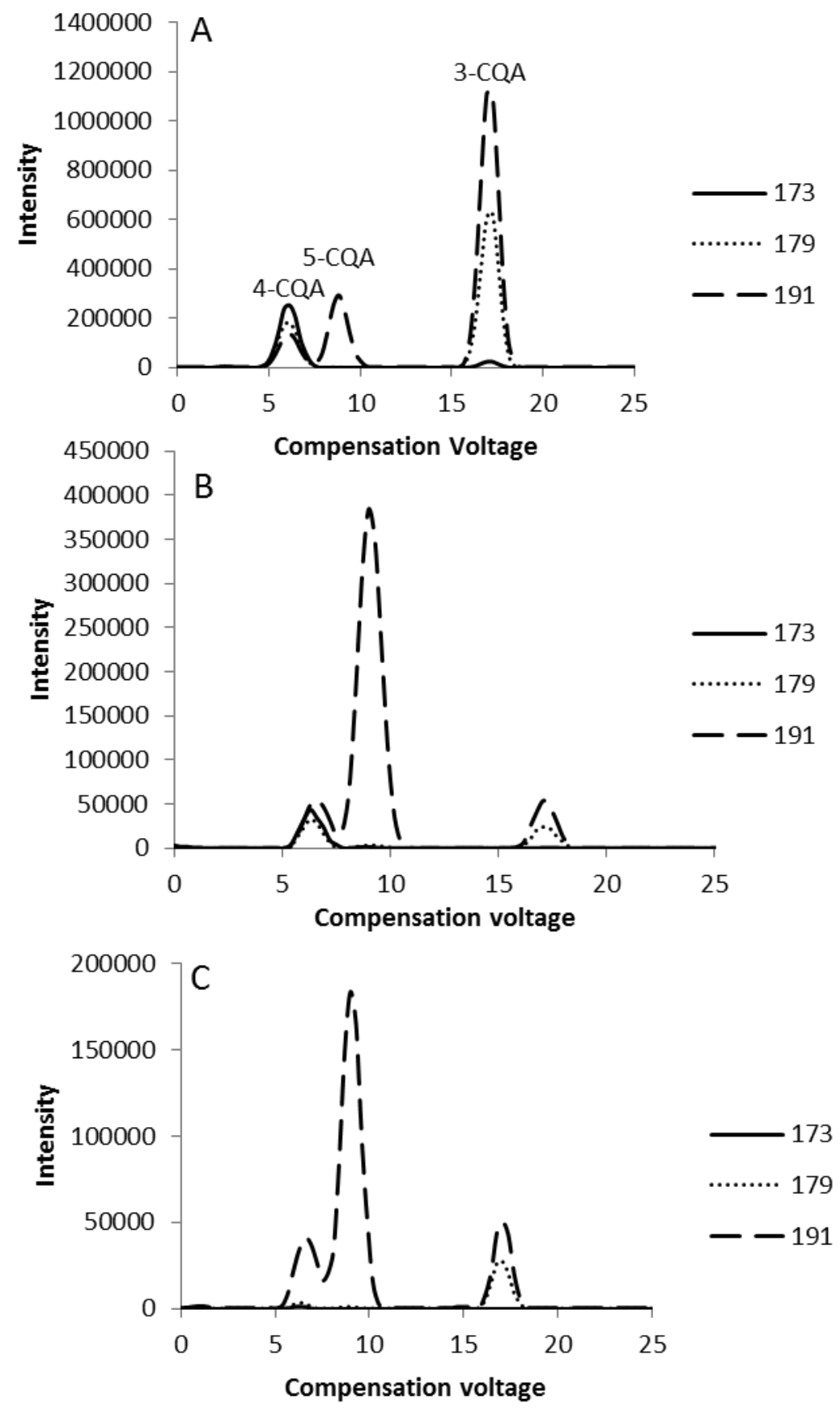

Figure 5. CV spectra for the mixed mono-caffeoylquinic acid isomer standards (A), and commercial apple (B) and pear juices (C). 
Cite this article as: Willems, J., Khamis, M.M., Saeid, W.M., et al. Anal Chim Acta. 2016 Aug 24; 933:16474. Final publication is available at: http://dx.doi.org/10.1016/j.aca.2016.05.041.

Table 1. Product ions of mono-caffeoylquinic acid isomers observed in the positive ion mode during CID-MS/MS analysis.

\begin{tabular}{lllllllllllll}
\hline Compound & $\begin{array}{c}\text { Precursor } \\
\text { Ion } \\
{[\mathbf{M}+\mathbf{H}]^{+}}\end{array}$ & 193 & 181 & 175 & 163 & 157 & 147 & 145 & 139 & 135 & 129 & 117 \\
& 355 & $\checkmark^{\mathrm{a}}$ & $\checkmark$ & $\checkmark$ & $\checkmark$ & $\checkmark$ & $\checkmark$ & $\checkmark$ & $\checkmark$ & $\checkmark$ & $\checkmark$ & $\checkmark$ \\
\hline 5-CQA & 355 & $\mathrm{~N}$ & $\checkmark$ & $\mathrm{N}$ & $\checkmark$ & $\mathrm{N}$ & $\mathrm{N}$ & $\checkmark$ & $\mathrm{N}$ & $\checkmark$ & $\mathrm{N}$ & $\checkmark$ \\
4-CQA & 355 & $\mathrm{~N}$ & $\checkmark$ & $\mathrm{N}$ & $\checkmark$ & $\mathrm{N}$ & $\mathrm{N}$ & $\checkmark$ & $\mathrm{N}$ & $\checkmark$ & $\mathrm{N}$ & $\checkmark$ \\
3-CQA & 355 & & & & & & & & & & & \\
\hline
\end{tabular}

a $\sqrt{ }$ : Present, N: Not observed

Table 2. Tabulated $\mathrm{MS}^{3}$ experiments in the positive ion mode (A) and the negative ion mode (B) for the monocaffeoylquinic acids.

\begin{tabular}{|c|c|c|}
\hline \multicolumn{3}{|c|}{ (A) Positive Ion Mode MS ${ }^{3}$ Analysis } \\
\hline Precursor Ion & $\begin{array}{l}\text { First Generation Product } \\
\text { Ions (MS/MS) }\end{array}$ & $\begin{array}{l}\text { Second Generation Product } \\
\text { Ions }\left(\mathrm{MS}^{3}\right)\end{array}$ \\
\hline \multirow[t]{7}{*}{355.1} & 193.1 & $175.0,157.3,147.0,129.2$ \\
\hline & 181.0 & $163.1,135.1$ \\
\hline & 175.0 & $157.3,147.0,139.1,129.2$ \\
\hline & 163.1 & $144.9,135.1,117.0$ \\
\hline & 144.9 & 117.0 \\
\hline & 135.1 & 117.0 \\
\hline & 117.0 & \\
\hline \multicolumn{3}{|c|}{ (B) Negative Ion Mode $\mathrm{MS}^{3}$ Analysis } \\
\hline Precursor Ion & $\begin{array}{l}\text { First Generation Product } \\
\text { Ions (MS/MS) }\end{array}$ & $\begin{array}{l}\text { Second Generation Product } \\
\text { Ions }\left(\mathrm{MS}^{3}\right)\end{array}$ \\
\hline \multirow[t]{7}{*}{353.2} & 190.7 & $\begin{array}{l}\text { 172.6, 155.0, 137.0, 127.1, } \\
110.6,108.9\end{array}$ \\
\hline & 178.8 & 134.8 \\
\hline & 172.6 & $155.0,137.0,110.6$ \\
\hline & 161.0 & \\
\hline & 155.0 & $137.0,110.6$ \\
\hline & 134.8 & \\
\hline & 127.1 & \\
\hline
\end{tabular}


Cite this article as: Willems, J., Khamis, M.M., Saeid, W.M., et al. Anal Chim Acta. 2016 Aug 24; 933:16474. Final publication is available at: http://dx.doi.org/10.1016/j.aca.2016.05.041.

\section{6}

Table 3. Major MS/MS product ions at $\mathrm{m} / \mathrm{z}$ 191, 179 and 173 (counts $>5.0 \times 10^{4}$ by $6550 \mathrm{iFunnel}$ QTOF) used for isomer identification.

\begin{tabular}{lccc}
\hline Compound & $\mathbf{1 9 1}$ & $\mathbf{1 7 9}$ & $\mathbf{1 7 3}$ \\
\hline 5-CQA & $\checkmark$ & & \\
4-CQA & $\checkmark$ & $\checkmark$ & $\checkmark$ \\
3-CQA & $\checkmark$ & $\checkmark$ & \\
\hline
\end{tabular}

